Please do not remove this page

RMIT

UNIVERSITY

\title{
A methodology for hydrocode analysis of ultra-high molecular weight polyethylene composite under ballistic impact
}

Nguyen, Long; Lassig, Torsten; Ryan, Shannon; Riedel, Werner; Mouritz, Adrian; Orifici, Adrian https://researchrepository.rmit.edu.au/esploro/outputs/9921860215301341/filesAndLinks?institution=61RMIT_INST\&index=null

Nguyen, L., Lassig, T., Ryan, S., Riedel, W., Mouritz, A., \& Orifici, A. (2016). A methodology for hydrocode analysis of ultra-high molecular weight polyethylene composite under ballistic impact. Composites Part A: Applied Science and Manufacturing, 84, 224-235. https://doi.org/10.1016/j.compositesa.2016.01.014 Document Version: Accepted Manuscript

Published Version: https://doi.org/10.1016/j.compositesa.2016.01.014

Repository homepage: https://researchrepository.rmit.edu.au (C) 2016 Elsevier Ltd

Downloaded On 2023/04/26 11:32:29 +1000 
Thank you for downloading this document from the RMIT Research Repository.

The RMIT Research Repository is an open access database showcasing the research outputs of RMIT University researchers.

RMIT Research Repository:http://researchbank.rmit.edu.au/

\section{Citation:}

Nguyen, L, Lassig, T, Ryan, S, Riedel, W, Mouritz, A and Orifici, A 2016, 'A methodology for hydrocode analysis of ultra-high molecular weight polyethylene composite under ballistic impact', Composites Part A: Applied Science and Manufacturing, vol. 84, pp. 224-235.

See this record in the RMIT Research Repository at:

https://researchbank.rmit.edu.au/view/rmit:36655

Version: Accepted Manuscript

Copyright Statement: (c) 2016 Elsevier Ltd This work is licensed under a Creative Commons Attribution-NonCommercial-NoDerivatives 4.0 International License.

Link to Published Version:

http://dx.doi.org/10.1016/j.compositesa.2016.01.014

\section{PLEASE DO NOT REMOVE THIS PAGE}




\section{A methodology for hydrocode analysis of ultra-high molecular weight polyethylene composite under ballistic impact}

Long H. Nguyen ${ }^{1,4}$, Torsten R. Lässig ${ }^{2}$, Shannon Ryan ${ }^{3}$, Werner Riedel ${ }^{2}$, Adrian P. Mouritz ${ }^{1}$, Adrian C. Orifici ${ }^{1}$

\footnotetext{
${ }^{1}$ School of Aerospace, Mechanical and Manufacturing Engineering, RMIT University, GPO Box 2476 Melbourne, Australia ${ }^{2}$ Fraunhofer Institute for High Speed Dynamics, Ernst-Mach-Institut, Eckerstraße 4, D-79104, Freiburg, Germany ${ }^{3}$ Defence Science and Technology Organisation, 506 Lorimer St, Fishermans Bend, Victoria 3207, Australia

${ }^{4}$ Defence Materials Technology Centre, 24 Wakefield St, Hawthorn, Victoria 3122, Australia
}

\section{Abstract}

Ballistic performance analysis of ultra-high molecular weight polyethylene (UHMW-PE) is critical for the design of armour systems against ballistic threats. However, no validated modelling strategy has been published in literature for UHMW-PE composite that captures the penetration and damage mechanisms of thick targets impacted between $900 \mathrm{~m} / \mathrm{s}$ to $2000 \mathrm{~m} / \mathrm{s}$. Here we propose a mechanistically-based and extensively validated methodology for the ballistic impact analysis of thick UHMW-PE composite. The methodology uses a nonlinear orthotropic continuum model that describes the composite response using a non-linear equation of state (EoS), orthotropic elastic-plastic strength with directional hardening and orthotropic failure criteria. Interlaminar failure is modelled by dividing the panel into sublaminates connected by breakable bonds. The model is extensively validated using experimental ballistic data for a wide range of UHMW-PE target thicknesses up to $102 \mathrm{~mm}$ against $12.7 \mathrm{~mm}$ and $20 \mathrm{~mm}$ calibre fragment simulating projectiles (FSPs) with impact velocities between 400 and $2000 \mathrm{~m} / \mathrm{s}$. Very good overall agreement with experimental results is seen for depth of penetration, ballistic limit and residual velocity, while the penetration mechanisms and target bulge behaviour are accurately predicted. The model can be used to reduce the volume of testing typically required to design and assess thick UHMW-PE composite in ballistic impact applications. 
Keywords: Polymer-matrix composites, Ballistic Impact Behaviour, Modelling, Polyethylene fibres

\section{Introduction}

Composites reinforced with ultra-high molecular weight polyethylene (UHMW-PE) fibres are increasingly being used in protection against ballistic threats due to their high resistance to penetration and low weight. The material shows a mass efficiency against fragment simulating projectiles (FSP) threats of $300 \%$ to $500 \%$ compared to armour steel and $130 \%$ to $160 \%$ for polymer matrix composites reinforced with aramid, carbon or glass fibre [1]. Due to the extensive deformation exhibited by UHMW-PE composite under ballistic impact, multiple large targets are required to determine a single ballistic limit velocity. Such testing can be prohibitively expensive when considering a range of thicknesses and armour configurations against multiple ballistic threat types. In order to reduce testing efforts, it is highly desirable to establish computationally efficient numerical models that accurately predict the ballistic response of the material.

Numerical simulation of UHMW-PE composite under ballistic impact presents a significant challenge due to the large difference between the in-plane and interlaminar mechanical properties. The in-plane tensile strength, for example is approximately three orders of magnitude greater than the out-of-plane tensile strength [2]. Such large differences promote numerical instabilities (e.g. zero energy deformation modes or hour glassing) and require complex constitutive models with many parameters to describe the material behaviour at the macro-scale.

Chocron et al. [3] proposed a meso-scale model of UHMW-PE composite that discretises the laminate into strips of fibre bundles. The approach uses a simple linear-elastic orthotropic material model to represent the fibre bundles, and was successful in predicting the response 
of UHMW-PE composite strips, layers $\left([0 / 90]_{2}\right)$, and targets up to $11.5 \mathrm{~mm}$ against $7.62 \mathrm{~mm}$ diameter FSPs. However, the computational cost of meso-scale models is very high, making them impractical for thick UHMW-PE composites where a large number of bundle elements would be needed. Other models have been proposed to analyse the ballistic impact response of UHMW-PE composite, including multi-scale [4] and continuum [5] approaches. However, only limited validation of these models for impact velocities below $900 \mathrm{~m} / \mathrm{s}$ has been performed and no validation has been conducted for higher impact velocities. At higher impact velocities, a non-linear equation of state (EoS) is required to account for the nonlinear shock compressibility of the material; this is not captured with these models.

Lässig et al. [2] conducted extensive experimental characterisation of UHMW-PE composite (Dyneema ${ }^{\circledR}$ HB26) and derived material parameters for a continuum non-linear orthotropic model (that includes a non-linear EoS) implemented in ANSYS $^{\circledR}$ AUTODYN $^{\circledR}$ [6-9]. With these parameters, the model was validated for the impact of $15 \mathrm{~mm}$ thick UHMW-PE plates by spherical projectiles travelling at hypervelocity $(2052 \mathrm{~m} / \mathrm{s}$ to $6591 \mathrm{~m} / \mathrm{s})$. The material dataset was recently used by Nguyen et al. [10] to model thicker UHWE-PE targets (up to 50 $\mathrm{mm}$ ) when impacted by FSPs at velocities below $2000 \mathrm{~m} / \mathrm{s}$. At these impact velocities, material strength becomes increasingly important in controlling the deformation and perforation responses. Results showed significant under-prediction of the ballistic limit due partly to premature through-thickness shear failure. This failure occurs as a result of coupling within the failure model, which is sensitive to the very weak through-thickness tensile properties of the material.

In this paper, a methodology is proposed for modelling the ballistic impact analysis of thick UHMW-PE composites using a hydrocode model that incorporates a non-linear EoS and an orthotropic elastic-plastic material definition with multiple failure modes. The in-plane and out-of-plane failure modes are decoupled in the bulk material through sub-laminate 
discretisation of the target. The model is validated against a large amount of experimental ballistic impact data recently reported by Nguyen et al. [11]. Validation includes ballistic limit $\left(\mathrm{V}_{50}\right)$ predictions for UHMW-PE composite targets up to $102 \mathrm{~mm}$ thick against $12.7 \mathrm{~mm}$ and $20 \mathrm{~mm}$ FSPs, as well as depth of penetration (DoP) of semi-infinite UHMW-PE composite targets against $20 \mathrm{~mm}$ FSP. Quantitative validation of the model is also made in terms of the target bulge geometry and apex and their dependence on the FSP velocity profile, and the plastic hinge position of the bulge in the composite.

\section{Ballistic Impact Model}

\subsection{UHMW-PE Material Model}

The non-linear orthotropic material model developed in [6-9] and implemented in ANSYS ${ }^{\circledR}$ AUTODYN ${ }^{\circledR}$ is used to model the ballistic impact response of UHMW-PE composite. The material model includes orthotropic coupling of the material volumetric and deviatoric responses, non-linear equation of state, orthotropic hardening, stress-based composite failure criteria, and orthotropic energy-based softening. The material parameters for the UHMW-PE composite that were used are detailed in Table 1. For completeness the model will be briefly described below; more details are given in $[2,7-9,12]$.

Table 1. Non-linear orthotropic material model parameters for UHMW-PE composite (Dyneema ${ }^{\circledR}$ HB26)

\begin{tabular}{ccccc}
\multicolumn{5}{c}{ EoS: Orthotropic } \\
\hline Parameter & Symbol & Value & Units & Source \\
\hline Reference Density & $\rho$ & 0.98 & $\mathrm{~g} / \mathrm{cm}^{3}$ & {$[13]$} \\
Young's Modulus 11 & $\mathrm{E}_{11}$ & $3.62 \times 10^{6}$ & $\mathrm{kPa}$ & {$[2]$} \\
Young's Modulus 22 & $\mathrm{E}_{22}$ & $5.11 \times 10^{7}$ & $\mathrm{kPa}$ & {$[14]$} \\
Young's Modulus 33 & $\mathrm{E}_{33}$ & $5.11 \times 10^{7}$ & $\mathrm{kPa}$ & {$[14]$} \\
Poisson's Ratio 12 & $\mathrm{v}_{12}$ & 0.013 & - & {$[2]$} \\
Poisson's Ratio 23 & $\mathrm{v}_{23}$ & 0 & - & {$[2]$} \\
Poisson's Ratio 31 & $\mathrm{v}_{31}$ & 0.5 & - & {$[2]$} \\
Shear Modulus 12 & $\mathrm{G}_{12}$ & $2.0 \times 10^{6}$ & $\mathrm{kPa}$ & $\mathrm{a}$ \\
Shear Modulus 23 & $\mathrm{G}_{23}$ & $1.92 \times 10^{5}$ & $\mathrm{kPa}$ & $\mathrm{a}$ \\
Shear Modulus 31 & $\mathrm{G}_{31}$ & $2.0 \times 10^{6}$ & $\mathrm{kPa}$ & $\mathrm{a}$ \\
\hline \multicolumn{7}{c}{ Volumetric Response: Shock } & & \\
\hline Grüneisen coefficient & $\Gamma$ & 1.64 & - & {$[15]$} \\
Parameter C1 & $\mathrm{c}_{0}$ & $3.57 \times 10^{3}$ & $\mathrm{~m} / \mathrm{s}$ & - \\
Parameter S1 & $\mathrm{s}$ & 1.3 & - & $\mathrm{b}$ \\
Reference Temperature & $\mathrm{T}_{0}$ & 293 & $\mathrm{k}$ & -
\end{tabular}

\begin{tabular}{|c|c|c|c|c|}
\hline \multicolumn{5}{|c|}{ Strength: Orthotropic Yield } \\
\hline Parameter & Symbol & Value & Units & Source \\
\hline Plasticity constant 11 & $\mathrm{~A}_{11}$ & 0.016 & - & - \\
\hline Plasticity constant 22 & $\mathrm{~A}_{22}$ & $6 \times 10^{-4}$ & - & - \\
\hline Plasticity constant 33 & $\mathrm{~A}_{33}$ & $6 \times 10^{-4}$ & - & - \\
\hline Plasticity constant 12 & $\mathrm{~A}_{12}$ & 0 & - & - \\
\hline Plasticity constant 13 & $\mathrm{~A}_{13}$ & 0 & - & - \\
\hline Plasticity constant 23 & $\mathrm{~A}_{23}$ & 0 & - & - \\
\hline Plasticity constant 44 & $\mathrm{~A}_{44}$ & 1 & - & - \\
\hline Plasticity constant 55 & $\mathrm{~A}_{55}$ & 1.7 & - & - \\
\hline Plasticity constant 66 & $\mathrm{~A}_{66}$ & 1.7 & - & - \\
\hline Eff. Stress \#1 & $\sigma_{\text {eff } \# 1}$ & $1.48 \times 10^{3}$ & $\mathrm{kPa}$ & - \\
\hline Eff. Stress \#2 & $\sigma_{\text {effi } \# 2}$ & & $\mathrm{kPa}$ & - \\
\hline Eff. Stress \#3 & $\sigma_{\text {eff }}+3$ & $2.7 \times 10^{4}$ & $\mathrm{kPa}$ & - \\
\hline Eff. Stress \#4 & $\sigma_{\text {eff } \# 4}$ & $4.0 \times 10^{4}$ & $\mathrm{kPa}$ & - \\
\hline Eff. Stress \#5 & $\sigma_{\text {eff } \# 5}$ & $5.0 \times 10^{4}$ & $\mathrm{kPa}$ & - \\
\hline Eff. Stress \#6 & $\sigma_{\text {eff } H 4}$ & $6.0 \times 10^{4}$ & $\mathrm{kPa}$ & - \\
\hline
\end{tabular}




\begin{tabular}{|c|c|c|c|c|}
\hline Specific Heat & $\mathrm{c}$ & $1.85 \times 10^{3}$ & $\mathrm{~J} / \mathrm{kgK}$ & [13] \\
\hline \multicolumn{5}{|c|}{ Failure: Orthotropic Softening } \\
\hline Parameter & Symbol & Value & Units & Source \\
\hline Tensile Failure Stress 11 & $\mathrm{~S}_{11}$ & $1.01 \times 10^{20}$ & $\mathrm{kPa}$ & disabled \\
\hline Tensile Failure Stress 22 & $\mathrm{~S}_{22}$ & $1.15 \times 10^{6}$ & $\mathrm{kPa}$ & {$[14]$} \\
\hline Tensile Failure Stress 33 & $\mathrm{~S}_{33}$ & $1.15 \times 10^{6}$ & $\mathrm{kPa}$ & [14] \\
\hline Maximum Shear Stress 12 & $\mathrm{~S}_{12}$ & $5.75 \times 10^{5}$ & $\mathrm{kPa}$ & $\mathrm{c}$ \\
\hline Maximum Shear Stress 23 & $\mathrm{~S}_{23}$ & $1.20 \times 10^{5}$ & $\mathrm{kPa}$ & {$[14]$} \\
\hline Maximum Shear Stress 31 & $\mathrm{~S}_{31}$ & $5.75 \times 10^{5}$ & $\mathrm{kPa}$ & $\mathrm{c}$ \\
\hline Fracture Energy 11 & $\mathrm{G}_{11 \mathrm{C}}$ & 790 & $\mathrm{~J} / \mathrm{m}^{2}$ & [2] \\
\hline Fracture Energy 22 & $\mathrm{G}_{22 \mathrm{C}}$ & 30 & $\mathrm{~J} / \mathrm{m}^{2}$ & $\mathrm{~d}$ \\
\hline Fracture Energy 33 & $\mathrm{G}_{33 \mathrm{C}}$ & 30 & $\mathrm{~J} / \mathrm{m}^{2}$ & $\mathrm{~d}$ \\
\hline Fracture Energy 12 & $\mathrm{G}_{12 \mathrm{C}}$ & $1.46 \times 10^{3}$ & $\mathrm{~J} / \mathrm{m}^{2}$ & d \\
\hline Fracture Energy 23 & $\mathrm{G}_{23 \mathrm{C}}$ & $1.46 \times 10^{3}$ & $\mathrm{~J} / \mathrm{m}^{2}$ & d \\
\hline Fracture Energy 31 & $\mathrm{G}_{31 \mathrm{C}}$ & $1.46 \times 10^{3}$ & $\mathrm{~J} / \mathrm{m}^{2}$ & d \\
\hline Damage Coupling Coefficient & $\mathrm{C}$ & 0 & - & disabled \\
\hline
\end{tabular}

\begin{tabular}{|c|c|c|c|c|}
\hline Eff. Stress \#7 & $\sigma_{\text {eff } \# 7}$ & $8.0 \times 10^{4}$ & $\mathrm{kPa}$ & - \\
\hline Eff. Stress \#8 & $\sigma_{\text {eff } \# 8}$ & $9.8 \times 10^{4}$ & $\mathrm{kPa}$ & - \\
\hline Eff. Stress \#9 & $\sigma_{\text {eff } \# 9}$ & $2.0 \times 10^{5}$ & $\mathrm{kPa}$ & - \\
\hline Eff. Stress \#10 & $\sigma_{\text {eff } 10}$ & $1.0 \times 10^{6}$ & $\mathrm{kPa}$ & - \\
\hline Eff. Plastic Strain \#1 & $\varepsilon_{\text {effH } 1}$ & 0 & - & - \\
\hline Eff. Plastic Strain \#2 & $\varepsilon_{\text {effH } 2}$ & 0.01 & - & - \\
\hline Eff. Plastic Strain \#3 & $\varepsilon_{\text {effH3 }}$ & 0.1 & - & - \\
\hline Eff. Plastic Strain \#4 & $\varepsilon_{\text {eff } \# 4}$ & 0.15 & - & - \\
\hline Eff. Plastic Strain \#5 & $\varepsilon_{\text {eff } \# 5}$ & 0.175 & - & - \\
\hline Eff. Plastic Strain \#6 & $\varepsilon_{\text {eff } \# 6}$ & 0.19 & - & - \\
\hline Eff. Plastic Strain \#7 & $\varepsilon_{\text {eff } \# 7}$ & 0.2 & - & - \\
\hline Eff. Plastic Strain \#8 & $\varepsilon_{\text {eff } \# 8}$ & 0.205 & - & - \\
\hline Eff. Plastic Strain \#9 & $\varepsilon_{\text {eff } \# 9}$ & 0.21 & - & - \\
\hline Eff. Plastic Strain \#10 & $\varepsilon_{\text {eff̈ } 10}$ & 0.215 & - & - \\
\hline \multicolumn{5}{|c|}{ Bonds: Sub-laminate Interface } \\
\hline Parameter & Symbol & Value & Units & Source \\
\hline Normal Strength & $\mathrm{S}_{\mathrm{N}}$ & $5.35 \times 10^{3}$ & $\mathrm{kPa}$ & {$[2,16]$} \\
\hline Shear Strength & $\mathrm{S}_{\mathrm{S}}$ & $7.85 \times 10^{3}$ & $\mathrm{kPa}$ & [3] \\
\hline \multicolumn{5}{|c|}{$\begin{array}{l}\text { e elastic modulus value. Under shear there is exponential ris } \\
\text { Since the elastic portion of the curve is small, the modulus } \\
\text { tire stress-strain curve. }\end{array}$} \\
\hline
\end{tabular}

\subsubsection{Equation of State}

The thermodynamic (EoS) response of a material and its ability to carry tensile and shear loads (strength) is typically treated separately within hydrocodes such that the stress tensor can be decomposed into volumetric and deviatoric components [17]. However, anisotropic materials exhibit coupling of these two responses, i.e. hydrostatic stresses lead to deviatoric strains and verse visa. Anderson et al. [18] proposed a constitutive formulation for anisotropic material which allows the use of the theory of shock waves for orthotropic materials with a limited amount of coupling of the volumetric and deviatoric responses in the elastic regime. Here the pressure is composed of the volumetric and deviatoric components, and is defined by:

$$
P=P\left(\varepsilon_{v o l}, e\right)-\frac{1}{3}\left(C_{11}+C_{21}+C_{31}\right) \varepsilon_{11}^{d}-\frac{1}{3}\left(C_{12}+C_{22}+C_{32}\right) \varepsilon_{22}^{d}-\frac{1}{3}\left(C_{13}+C_{23}+C_{33}\right) \varepsilon_{33}^{d}
$$

where $C$ are coefficients of the stiffness matrix and $\varepsilon_{11,22,3 s}^{d}$ are the deviatoric strains in the principal directions. The pressure contribution from the volumetric strain $P\left(\varepsilon_{v o l}, e\right)$ is described using the Mie-Grüneisen EoS: 


$$
P\left(\varepsilon_{v o l}, e\right)=P_{r}(v)+\frac{\Gamma(v)}{v}\left[E-E_{r}(v)\right]
$$

where $v$ is the volume, $e$ is the internal energy and $\Gamma(v)$ is the Grüneisen coefficient. $\mathcal{P}_{r}(v)$ and $E_{r}(v)$ refer to a reference pressure and internal energy, respectively. The shock Hugoniot is typically used as a reference condition.

The shock formulation of the Mie-Grüneisen EoS is applied here, where an empirical linear relationship defines the shock and particle velocity relationship:

$$
U_{S}=c_{0}+S u_{p}
$$

where $U_{S}$ is the shock wave velocity, $c_{0}$ is the bulk sound speed, $S$ is the slope of the shockparticle velocity curve, and $u_{p}$ is the particle velocity. The reference pressure, density and internal energy are then calculated from the Rankine-Hugoniot equations. Conditions off the Hugoniot reference curve are approximated with the Grüneisen coefficient $(\Gamma)$ from the second term in Eq. (2).

In the non-linear orthotropic model, $c_{0}$ is calculated from the elastic orthotropic constants and the slope of the $U_{S}-u_{p}$ relationship, $S$, is empirically adjusted to match flyer plate impact test results. The shock response of UHMW-PE composite has previously been shown by Hazell et al. [19] to be similar to that of polyethylene, therefore it is assumed the off Hugoniot response of UHMW-PE composite is also similar. Thus, a Grüneisen coefficient for polyethylene of 1.64 is used in this work [15].

Figure 1 shows measurements by Lässig et al. [2] of the free surface velocity determined by inverse planar plate impact tests on UHMW-PE composite plates. Using the model, numerical results from one-dimensional simulations are also plotted, demonstrating good agreement of the initial and subsequent release waves up to about $3000 \mathrm{~ns}$ to $3500 \mathrm{~ns}$ post impact. After this time the one-dimensional strain assumption used in the simulation is no 
longer valid because the stress waves propagating from the lateral edge of the target specimen affect the free surface velocity measurements. The numerical curves have been produced through empirical adjustment of the $S$ parameter, thereby describing correctly the non-linear shock compressibility.

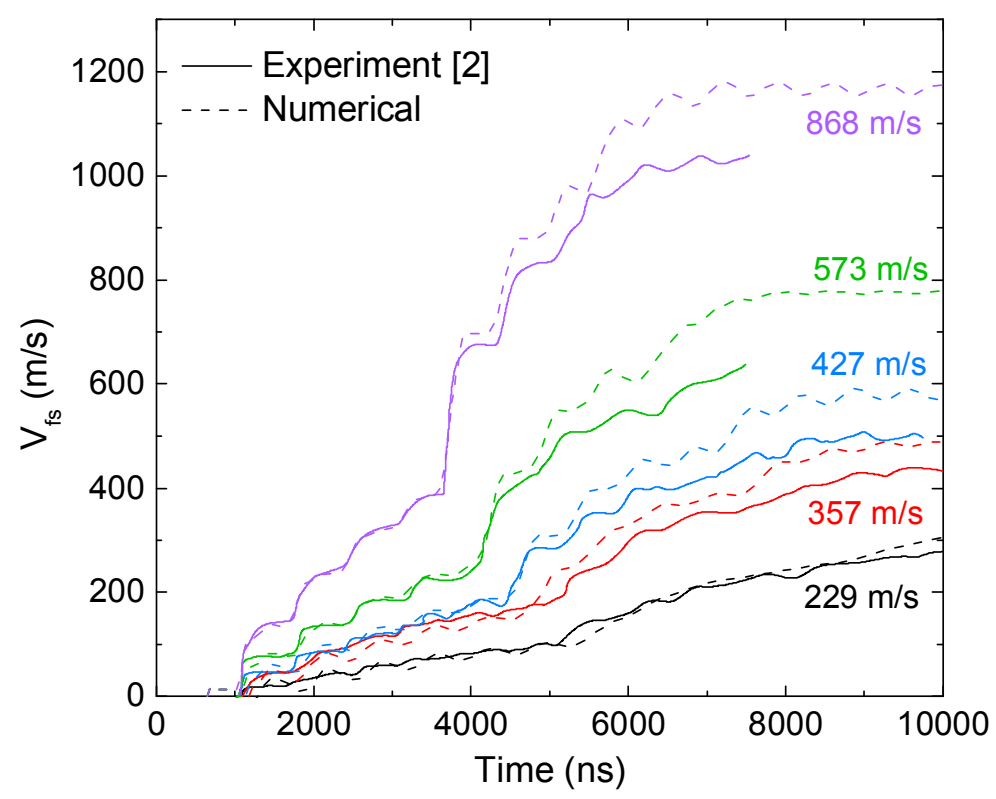

Figure 1. Free surface velocity trace from inverse plate impact test and numerical validation.

\subsubsection{Strength Model}

The quadratic yield surface proposed by Chen et al. [20] is used to describe non-linear, irreversible hardening of the material:

$$
\begin{gathered}
f\left(\sigma_{i j}\right)=a_{11} \sigma_{11}^{2}+a_{22} \sigma_{22}^{2}+a_{33} \sigma_{33}^{2}+2 a_{12} \sigma_{11} \sigma_{22}+2 a_{23} \sigma_{22} \sigma_{33} \\
+2 a_{13} \sigma_{11} \sigma_{33}+2 a_{44} \sigma_{23}^{2}+2 a_{55} \sigma_{31}^{2}++2 a_{66} \sigma_{12}^{2}=k
\end{gathered}
$$

where the nine plasticity coefficients, ${ }^{a_{i j}}$, represent the degree of plastic anisotropy of the material, ${ }^{\sigma_{i j}}$ are stresses in the principal material directions, and $k$ is a state variable that defines the current limit of the yield surface. To describe strain hardening, $k$ is replaced by a master effective stress-effective plastic strain curve, defined by 10 piecewise points. It allows the determination of the stress states in any orthotropic direction from the plasticity 
coefficients ${ }^{a_{i j}}$. The effective stress $\bar{\sigma}$ and effective plastic strain $\bar{\varepsilon}^{p}$ in the normal direction is defined by:

$$
\bar{\sigma}=\sigma_{i i} \sqrt{\frac{3 a_{i i}}{2}} \quad \text { and } \quad \bar{\varepsilon}^{p}=\varepsilon_{i i} \sqrt{\frac{2}{3 a_{i i}}}
$$

and the shear direction by:

$$
\bar{\sigma}=\sigma_{i j} \sqrt{3 a_{i j}} \quad \text { and } \quad \bar{\varepsilon}^{p}=\frac{\varepsilon_{i j}}{\sqrt{3 a_{i j}}}
$$

The master effective stress-effective plastic strain curve is best defined in the plane that experiences the largest non-linear plastic deformation. In the present work the in-plane shear stress-strain curve is used, and the corresponding plasticity coefficient $a_{44}$ is set to one. The other plasticity coefficients are set where possible to match experimental stress-strain curves for the other orthotropic directions.

\subsubsection{Failure Model}

Failure in the non-linear orthotropic model is based on a combined stress criterion and is initiated when:

$$
\left(\frac{\sigma_{i i}}{S_{i i}\left(1-D_{i i}\right)}\right)^{2}+\left(\frac{\sigma_{i j}}{S_{i j}\left(1-D_{i j}\right)}\right)^{2}+\left(\frac{\sigma_{k i}}{S_{k i}\left(1-D_{k i}\right)}\right)^{2} \geq 1 \text { for } i, j, k=1,2,3
$$

where $S_{i i}$ is the failure strength of the material in the respective directions. The damage parameter, $D_{i k}$, follows a linear relationship with stress and strain and is defined by:

$$
D_{i i}=\frac{L \sigma_{i i, f} \varepsilon_{c r}}{2 G_{i i, f}}
$$

where $L$ is the characteristic cell length, $\varepsilon_{c r}$ is the crack strain (strain above the failure initiation strain) and $G_{i i, f}$, the fracture energy in the direction of damage. 

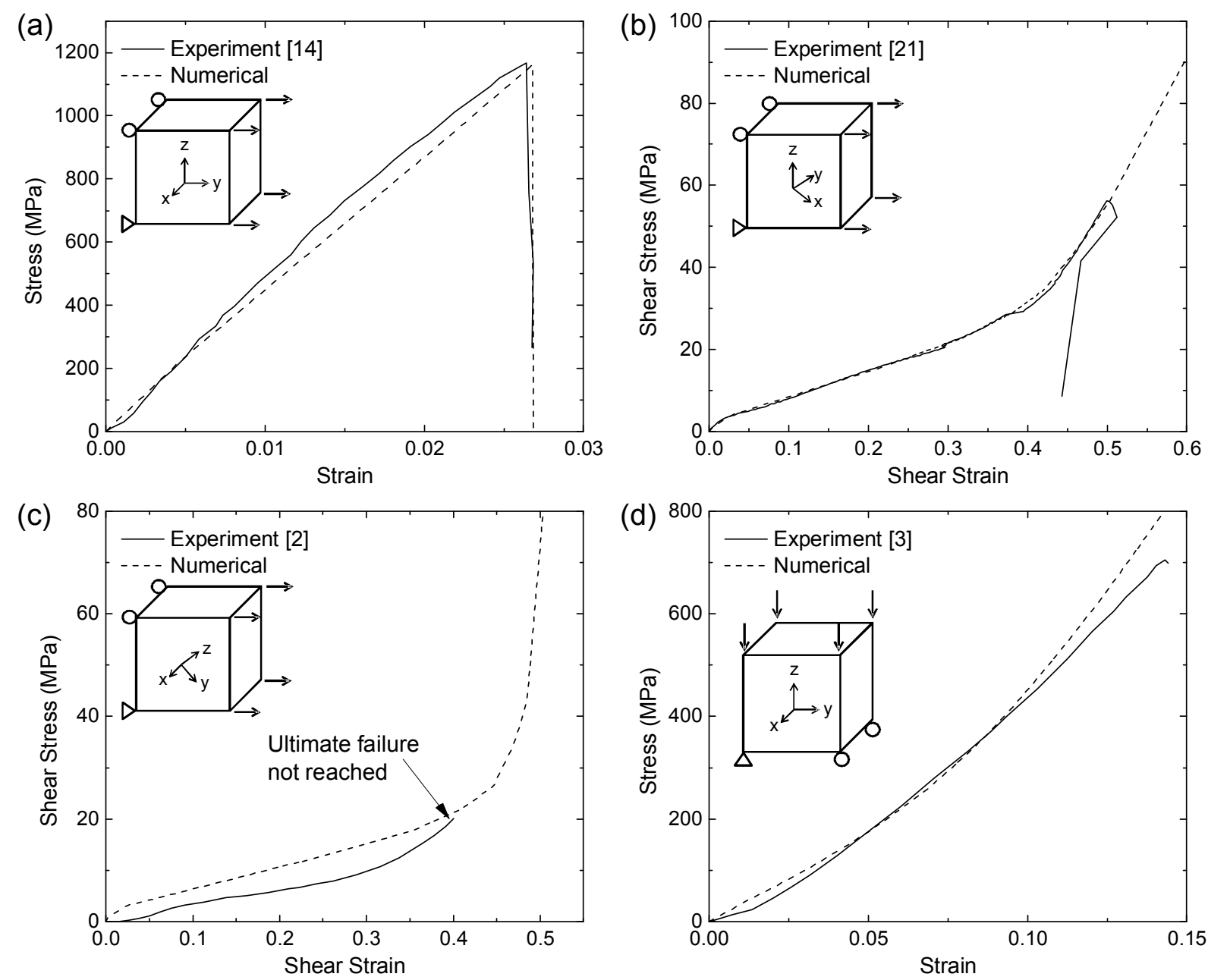

Figure 2. Stress-strain curves from single element simulations compared to experiments. (a) in-plane tension, (b) in-plane shear, (c) out-of-plane shear and (d) out-of-plane compression.

The strength and failure model is verified against mechanical test results for UHMW-PE composite (Dyneema ${ }^{\circledR}$ HB26) under uniaxial tension, compression and shear from a number of different sources $[2,3,14,21]$. The numerical verification involves simulation of a single element under the appropriate loading and boundary conditions; the results of which are shown in Figure 2. The numerical model is shown to provide good agreement for the in-plane tension and reasonable agreement for the out-of-plane compression simulation. The in-plane shear simulation is also in good agreement; however failure occurs at a higher stress in the numerical model. The experimental curve is from a $45^{\circ}$ in-plane tension test, for which failure measurements are known to be dependent to specimen geometry [22]. For example, Lässig et 
al. [21] measured failure strengths between $35 \mathrm{MPa}$ and $55 \mathrm{MPa}$ for an UHMW-PE specimen with a $20 \mathrm{~mm}$ gauge width tested at different loading rates. Experiments performed by Heisserer [14] on the same material with a gauge width of $80 \mathrm{~mm}$ gave failure stresses greater than $120 \mathrm{MPa}$. Since validation of the model is ultimately performed on ballistic panels with lateral dimensions greater than $300 \mathrm{~mm}$, the larger value is taken.

The agreement for out-of-plane shear stress-strain is not as good, yet still reasonable (Figure 2(c)). This is due to the simplification of the strength model, which describes all stress states in the principal directions as scalable with respect to the master effective stress-effective plastic strain curve by one single plasticity constant per loading mode. In through-thickness shear experiments conducted by Lässig et al. [2], measurements were not made for shear strains greater than 0.4 , at which point the specimen had not completely failed. At high shear strains fibre realignment occurs, resulting in a significant increase in the slope (as seen in [2]). This behaviour is shown to be replicated in the model. Under this loading condition complete failure occurs due to either fibre tensile failure as a result of fibre realignment, or fibre shearing. As such, the principal stress is used to determine the maximum out-of-plane failure shear stress for the specimen under uniaxial in-plane tension:

$$
S_{12,31}=\frac{S_{22,33}}{2}
$$

This provides a value of $575 \mathrm{MPa}$, which is similar to $560 \mathrm{MPa}$ that was used successfully by Nguyen et al. [11] in an analytical model to predict the ballistic penetration of thick UHMWPE composite.

\subsection{Target Erosion Model}

When modelling ballistic impact events on isotropic materials using Lagrangian discretisation, large element distortion occurs that affects time step and numerical stability. 
Erosion models based on effective strain have been used to successfully overcome this issue [23], where the effective strain is defined as [24]:

$$
\varepsilon_{e f f}=\frac{2}{3}\left[\left(\varepsilon_{11}^{2}+\varepsilon_{22}^{2}+\varepsilon_{33}^{2}\right)-\left(\varepsilon_{11} \varepsilon_{22}+\varepsilon_{22} \varepsilon_{33}+\varepsilon_{33} \varepsilon_{11}\right)+3\left(\varepsilon_{12}^{2}+\varepsilon_{23}^{2}+\varepsilon_{31}^{2}\right)\right]^{1 / 2}
$$

However, such formulation is inappropriate for anisotropic materials because the failure strains can be substantially different in different directions due to the directionally-dependant nature of fibre-reinforced composites. When failure occurs in one direction, the corresponding stiffness in that direction is set to zero. This leads to large strains in that direction, which in the case of impact and penetration can be as excessive as the driving force of the impactor continues to expand the element. If the strains in the other directions remain small, then the effective strain does not capture these extreme strains as the calculation has an averaging effect. Furthermore, due to the continuum definition, as the strains increase significantly in one direction following failure, the overall volume of the element increases. This has the effect of artificially preventing failure in the other directions, as forces in these directions generate lower stresses due to the increased volume. This effect becomes more pronounced at the excessive strains seen in penetration simulations.

A new damage-based erosion model was written in a user subroutine to address this problem. In this model, elements are eroded only when they are fully damaged in the in-plane (fibre) direction, which is defined by:

$$
\begin{aligned}
& D_{22}=1 \\
& D_{33}=1
\end{aligned}
$$

Failure of elements in the fibre direction also leads to a loss of strength in the associated shear directions, so the above criterion also accounts for elements failing under shear. An outof-plane criterion (e.g. in the 11 direction) is not included because out-of-plane failure, as will be discussed in the following section, is modelled between the sub-laminate interfaces 
through bonded contacts. A global instantaneous erosion strain of $150 \%$ was additionally applied to delete any highly distorted elements which affect the time step and numerical stability without playing a further role on the target interaction.

Figure 3 shows the velocity profile of simulations computed using the effective strain criterion (IGS, or instantaneous geometric strain in AUTODYN ${ }^{\circledR}$ ) with an effective strain of $250 \%$ (IGS2.5) and 150\% (IGS1.5), in comparison with simulation results using the damagebased criterion (DMG). Cross-sections from the IGS2.5 numerical analysis at two points, A and B, are shown with contours of in-plane material damage. Experimental results are also shown, where the experimental residual velocity and perforation time are indicated together with shaded regions corresponding to the typical experimental variance. The results show that using the IGS erosion model with an effective strain of $250 \%$, at $30 \mu$ s after impact (point A), the model has predicted complete failure through the thickness of the target. However, the projectile velocity continues to reduce beyond this point in time. At $200 \mu \mathrm{s}$ after impact (point B), the failed elements have elongated significantly but the projectile velocity still continues to decrease. In reality, this failed material would no longer be influencing the projectile. The unrealistic behaviour is an artefact of the strain-based erosion model for an anisotropic material. Decreasing the effective strain to $150 \%$ reduces the extent of this unrealistic behaviour, but does not eliminate it completely. In contrast, the damage-based erosion model gives accurate predictions of the residual velocity and perforation time, in addition to more realistic representations of the material performance as shown at point $\mathrm{C}$ in Figure 3. 

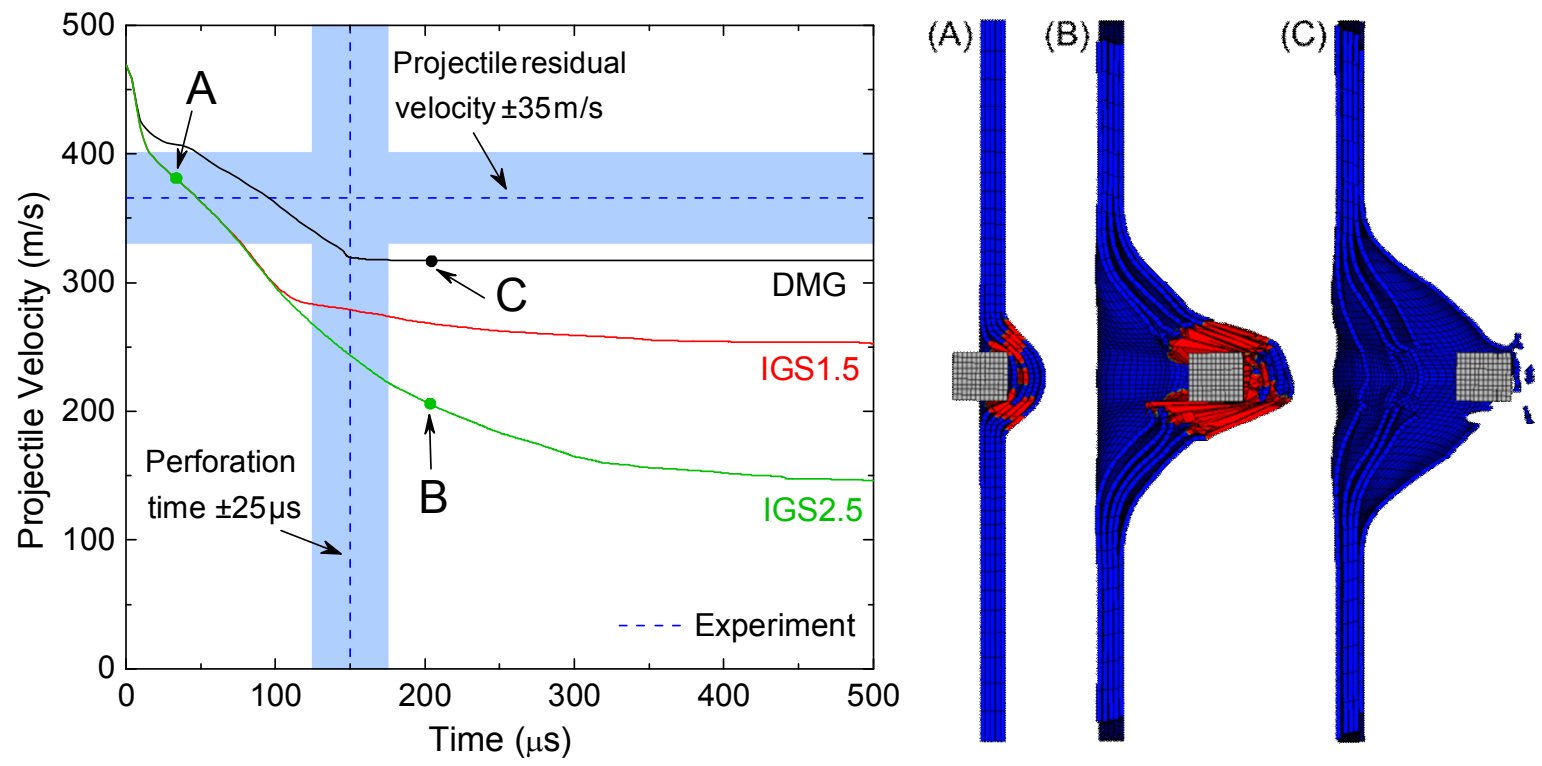

Figure 3. Projectile residual velocity versus time from impact for $10 \mathrm{~mm}$ thick targets impacted by $20 \mathrm{~mm}$ FSP at $469 \mathrm{~m} / \mathrm{s}$. Right images are cross-section contours through the model mid-plane from the IGS2.5 configuration, corresponding to points on the velocity profiles, where red indicates elements that have failed in the in-plane direction and blue indicates no in-plane failure.

\subsection{Target model}

The ballistic limit tests performed in [11] used targets measuring $300 \mathrm{~mm} \times 300 \mathrm{~mm}$ except for the $76 \mathrm{~mm}$ and $102 \mathrm{~mm}$ thick panels which had lateral dimensions of $400 \mathrm{~mm} \times 400 \mathrm{~mm}$. The full target is modelled (i.e. no symmetry) because the material is orthotropic and the projectile is asymmetric. In ANSYS ${ }^{\circledR}$ AUTODYN $^{\circledR}$, the out-of-plane direction is designated as the 11 material direction and the in-plane directions are the 22 and 33 directions. The model used 8-node hexahedral elements and the target was discretised into sub-laminates; to form multiple layers through the laminate thickness. A stack of sub-laminates is generated, with each sub-laminate one element thick, separated by a small gap. This gap was $0.06 \mathrm{~mm}$ for targets impacted by $12.7 \mathrm{~mm}$ FSP or $0.1 \mathrm{~mm}$ for targets impacted by $20 \mathrm{~mm}$ FSP to satisfy the master-slave contact (external gap) algorithm used to detect contact between the different bodies. While the addition of these gaps increased the total thickness of the target, the actual thickness of the target was only considered to be occupied by material, i.e the sum 
of the thickness of all of the sub-laminates. The sum of all the gaps was small $(<5 \%)$ compared to the total thickness of the target and was considered to have negligible effects on the ballistic performance.

The element dimension of the target sub-laminates were approximately uniform (aspect ratio of 1) and equal to the projectile mesh size at the impact site. After extending to a radius of one projectile diameter from the penetration zone, the mesh size was radially graded. The mesh size was controlled by the number of elements across the projectile diameter, and the need to maintain the same element size between the projectile and the target penetration zone. Matching the projectile and target mesh is critical in order to avoid a stiffness mismatch due to the relative mesh size of the target and projectile.

Mesh refinement was performed for a DoP test to determine the thickness of the sub-laminate and the size of the elements in the penetration zone. Table 2 shows the cases considered and the resulting number of sub-laminates in the laminate, sub-laminate thickness (also the inplane element length around penetration zone), the predicted depth of penetration and the percentage difference ( $\%$ Diff) in depth of penetration relative to the case with the finest mesh. The projectile velocity profile is also important to consider for this mesh refinement study and is shown in Figure 4 for the different cases.

Table 2. Mesh refinement study results on $100 \mathrm{~mm}$ DoP target impacted by $20 \mathrm{~mm}$ FSP at $1140 \mathrm{~m} / \mathrm{s}$.

\begin{tabular}{ccccc}
\hline $\begin{array}{c}\text { Elements across } \\
\text { projectile diameter }\end{array}$ & $\begin{array}{c}\text { Number of } \\
\text { sub-laminates }\end{array}$ & $\begin{array}{c}\text { Sub-laminate } \\
\text { thickness }(\mathrm{mm})\end{array}$ & $\begin{array}{c}\text { DoP } \\
(\mathrm{mm})\end{array}$ & \% Diff \\
\hline 6 & 30 & 3.3 & 46.6 & -14.5 \\
9 & 50 & 2.0 & 52.0 & -4.6 \\
12 & 60 & 1.7 & 53.3 & -2.2 \\
15 & 75 & 1.3 & 54.5 & 0.0 \\
\hline
\end{tabular}




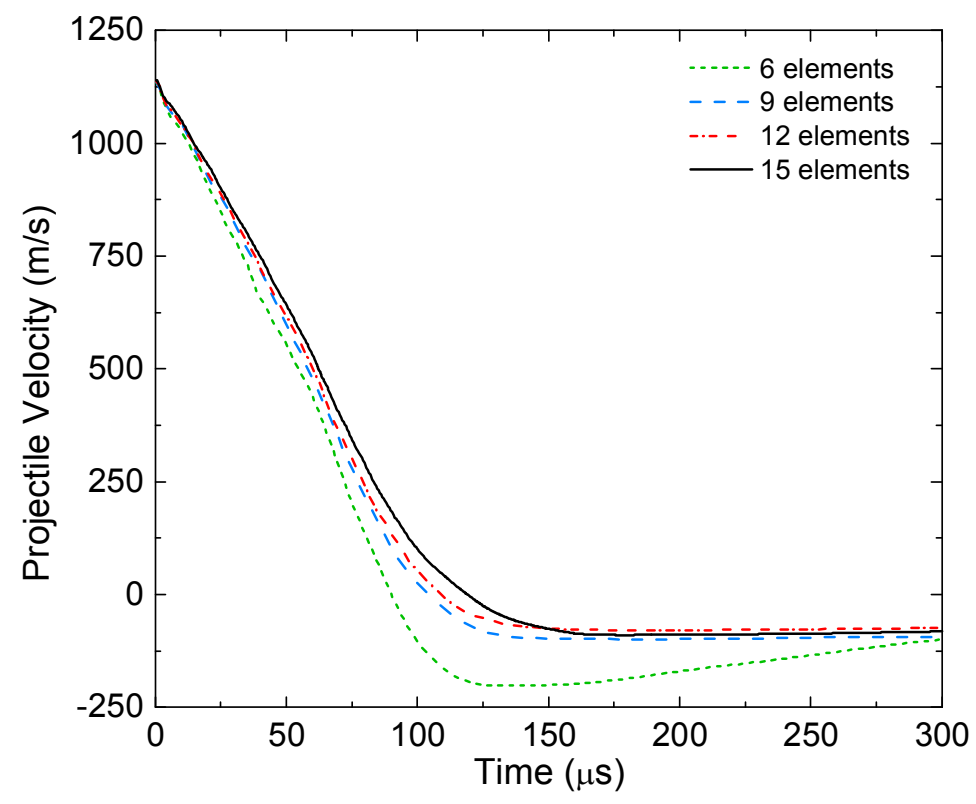

Figure 4. Projectile velocity profile results from mesh refinement study on $100 \mathrm{~mm}$ DoP target impacted by $20 \mathrm{~mm}$ FSP at $1140 \mathrm{~m} / \mathrm{s}$.

In this study, satisfactory convergence was reached for cases where there were 9 or more elements across the projectile diameter, which corresponds to element size around the penetration zone and sub-laminate thickness of $2 \mathrm{~mm}$. This meshing scheme was used for all targets impacted by $20 \mathrm{~mm}$ FSP. For targets impacted by the $12.7 \mathrm{~mm}$ FSP, 9 elements across the projectile diameter was also used, giving element size around the penetration zone and sub-laminate thickness of $1.4 \mathrm{~mm}$.

The sub-laminates were kinematically joined together using a bonded contact that was breakable through a criterion combining normal and shear stresses:

$$
\left(\frac{\sigma_{N}}{S_{N}}\right)^{a}+\left(\frac{\sigma_{S}}{S_{S}}\right)^{b} \geq 1
$$

where $\sigma$ and $S$ are stress and strength values, subscripts $N$ and $S$ are the normal and shear directions respectively, and the exponents $a$ and $b$ were assumed to be 1.0 due to the absence of combined loading data. No high strain rate experiments have been reported for 
UHMW-PE composite, which would allow a determination of the through-thickness tensile and shear strengths at ballistic conditions. These properties are dominated by the matrix material, which is both highly strain-rate and pressure-dependent $[3,25]$.

Dynamic spallation tests performed by Riedel et al. [16] on carbon and aramid fibre reinforced composites have shown through-thickness tensile strength to be between 2 to 5 times higher than quasi-static values [16]. Based on this, the quasi-static through-thickness tensile strength value for UHMW-PE composite (1.07 MPa [2]) was multiplied by a factor of 5, to determine an approximate high strain rate value. The interlaminar shear strength of UHMW-PE composite was characterised in [3] at $500 \mathrm{MPa}$ of hydrostatic pressure. The high pressure value determined is 3 times higher than the value under atmospheric conditions, as the initiation and propagation of cracks are inhibited under hydrostatic pressure [26]. The high pressure interlaminar strength was used in this work, as it more closely approximates ballistic conditions where high pressure propagates through the material upon impact.

No boundary conditions were imposed on the target because high speed video of ballistic impact tests typically showed clamp slippage upon impact due to the low friction coefficient of UHMW-PE composite [11].

\subsection{Projectile model}

The FSP is made from 4340H steel with a Rockwell C hardness of 30 (MIL-DTL-46593B [27]). The material was described using the Johnson-Cook strength model [28] and the shock formulation of the Mie-Grüneisen EoS, the parameters for which are shown in Table 3. 
Table 3. FSP material parameters

\begin{tabular}{lcccc} 
EoS: Shock & & & & \\
\hline Parameter & Symbol & Value & Units & Source \\
\hline Density & $\rho$ & 7.88 & $\mathrm{~g} / \mathrm{cm}^{3}$ & {$[29]$} \\
Gruneisen coefficient & $\Gamma$ & 2.17 & - & {$[15]$} \\
Parameter C1 & $\mathrm{c}_{0}$ & $4.57 \times 10^{3}$ & $\mathrm{~m} / \mathrm{s}$ & {$[15]$} \\
Parameter S1 & $\mathrm{s}$ & 1.49 & - & {$[15]$} \\
Reference Temperature & $\mathrm{T}_{0}$ & 300 & $\mathrm{k}$ & - \\
Specific Heat & & 477 & $\mathrm{~J} / \mathrm{kgK}$ & {$[28]$} \\
\hline
\end{tabular}

Strength: Johnson-Cook

\begin{tabular}{lcccc}
\multicolumn{1}{c}{ Parameter } & Symbol & Value & Units & Source \\
\hline Shear Modulus & $\mathrm{G}$ & $7.78 \times 10^{7}$ & $\mathrm{kPa}$ & {$[29]^{*}$} \\
Yield Stress & $\mathrm{A}$ & $1.03 \times 10^{7}$ & $\mathrm{kPa}$ & {$[29]$} \\
Hardening Constant & $\mathrm{B}$ & $4.77 \times 10^{7}$ & $\mathrm{kPa}$ & {$[28]$} \\
Hardening Exponent & $\mathrm{n}$ & 0.18 & - & {$[28]$} \\
Strain Rate Constant & $\mathrm{C}$ & 0.012 & - & {$[28]$} \\
Thermal Softening Exponent & $\mathrm{m}$ & 1.0 & - & {$[28]$} \\
Melting Temperature & $\mathrm{T}_{\mathrm{M}}$ & 1763 & $\mathrm{~K}$ & {$[28]$} \\
Ref. Strain Rate & $\dot{c}_{0}$ & 1.0 & $\mathrm{~s}^{-1}$ & {$[28]$} \\
\hline
\end{tabular}

* calculated from an elastic modulus of $207 \mathrm{GPa}$ and Poisson ratio of 0.33

The Johnson-Cook strength model parameters for $4340 \mathrm{H}$ steel were based on those of Steel S-7 [28] with a reduction in the yield strength from $1590 \mathrm{MPa}$ to $1030 \mathrm{MPa}$ to reflect the reported yield strength of $4340 \mathrm{H}$ steel [29]. The parameters for strain and strain rate hardening were unchanged. Parameters for the shock EoS of steel were taken from [15]. Simulations with this material model and parameter set showed similar levels of projectile deformation compared to the experiment for the range of impact velocities investigated (Figure 5).
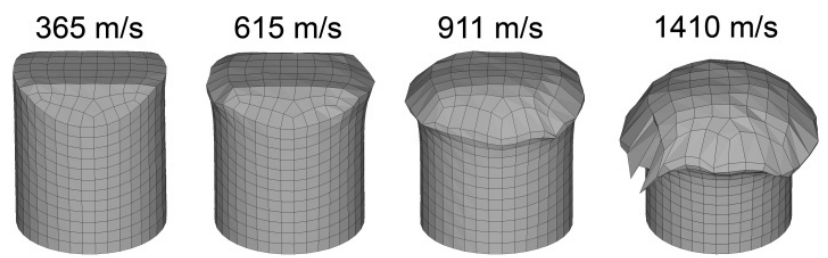

$1966 \mathrm{~m} / \mathrm{s}$
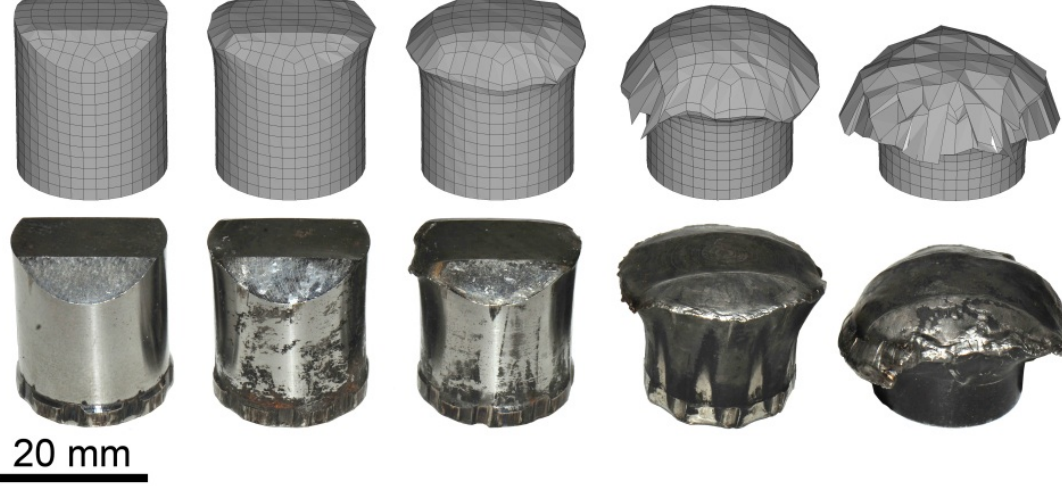

$20 \mathrm{~mm}$

Figure 5. Projectile deformation in the numerical simulation (top) and experiments (bottom). 


\section{Results \& Discussion}

\subsection{Depth of Penetration of Semi-Infinite Targets}

Experimental depth of penetration values for semi-infinite UHMW-PE composite targets against $20 \mathrm{~mm}$ FSP [11] are used as a first step to validate and assess the accuracy of the numerical model. In these tests, $100 \mathrm{~mm}$ and $150 \mathrm{~mm}$ thick $150 \mathrm{~mm} \times 150 \mathrm{~mm}$ targets were impacted by a $20 \mathrm{~mm}$ FSP. The targets were backed by a $100 \mathrm{~mm}$ thick steel plate to prevent back face deformation of the UHMW-PE target. Experimentally, the DoP was measured from the difference between the original panel thickness and the remaining unperforated thickness after ballistic impact. Numerically the DoP was determined from the sum of all perforated sub-laminates.

Numerical simulations were performed with and without a steel backing, though no discernible difference in penetration depth was seen for the two cases. The DoP results obtained by modelling and experimentation are given in Table 4 and are plotted in Figure 6 .

Comparison with experiment shows excellent agreement, with both experiment and simulation predicting a linear relationship between DoP and impact velocity.

Table 4. Depth of penetration results

\begin{tabular}{ccccc}
\hline $\begin{array}{c}\text { Target } \\
\text { Thickness }(\mathrm{mm})\end{array}$ & $\begin{array}{c}\text { Impact } \\
\text { Velocity }(\mathrm{m} / \mathrm{s})\end{array}$ & $\begin{array}{c}\text { DoP Experiment } \\
(\mathrm{mm})\end{array}$ & $\begin{array}{c}\text { DoP Numerical } \\
(\mathrm{mm})\end{array}$ & Diff $(\%)$ \\
\hline 100 & 815 & 30.0 & 30 & 0.0 \\
150 & 991 & 39.8 & 40 & 0.5 \\
150 & 1038 & 45.2 & 44 & -2.7 \\
150 & 1305 & 61.4 & 60 & -2.3 \\
\hline
\end{tabular}




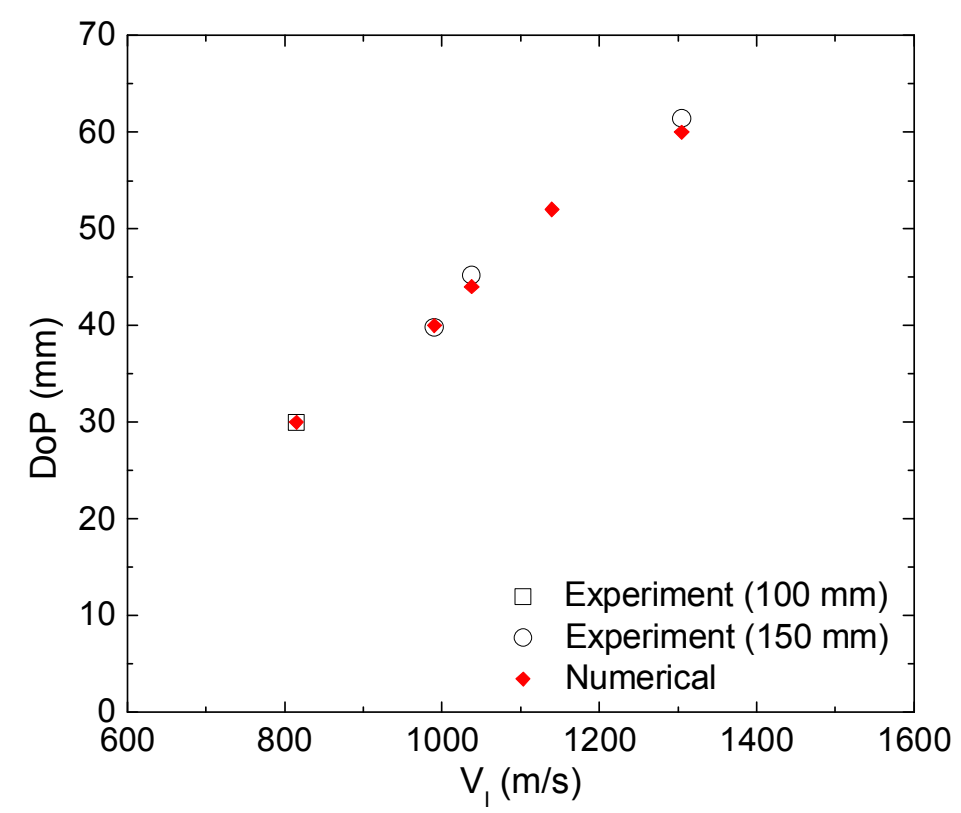

Figure 6: Depth of penetration results for $20 \mathrm{~mm}$ FSP impacts against semi-infinite UHMWPE composite.

\subsection{Ballistic Performance of Finite Thickness Targets}

Simulations were conducted to predict the ballistic limit velocity of various thicknesses of UHMW-PE composite panels against $12.7 \mathrm{~mm}$ and $20 \mathrm{~mm}$ FSP. The number for sublaminates used to model the target for various target thicknesses is shown in Table 5. The targets were impacted over a range of impact velocities requiring one partial penetration and at least three complete penetrations. The residual velocities of the FSPs following target perforation were fit to the Lambert-Jonas equation [30], Eq.(13), from which an estimate of the ballistic limit was determined:

$$
V_{R}=a\left(V_{I}^{p}-V_{B L}^{p}\right)^{1 / p}
$$

where $V_{R}$ is the residual velocity, $V_{I}$ is the impact velocity and $V_{B L}$ is the ballistic limit velocity. $V_{B L}, a$ and $p$ are determined from regression analysis of the impact and residual velocity results. The results of the Lambert-Jonas analysis are shown in Figure 7. Nguyen et al. [11] used high speed photography to measure the projectile residual velocity in experimental ballistic tests on $10 \mathrm{~mm}$ and $20 \mathrm{~mm}$ UHMW-PE composite targets against 
$20 \mathrm{~mm}$ FSPs . These measurements are plotted in Figure 7 for comparison. The numerical results show excellent agreement with the experiments.
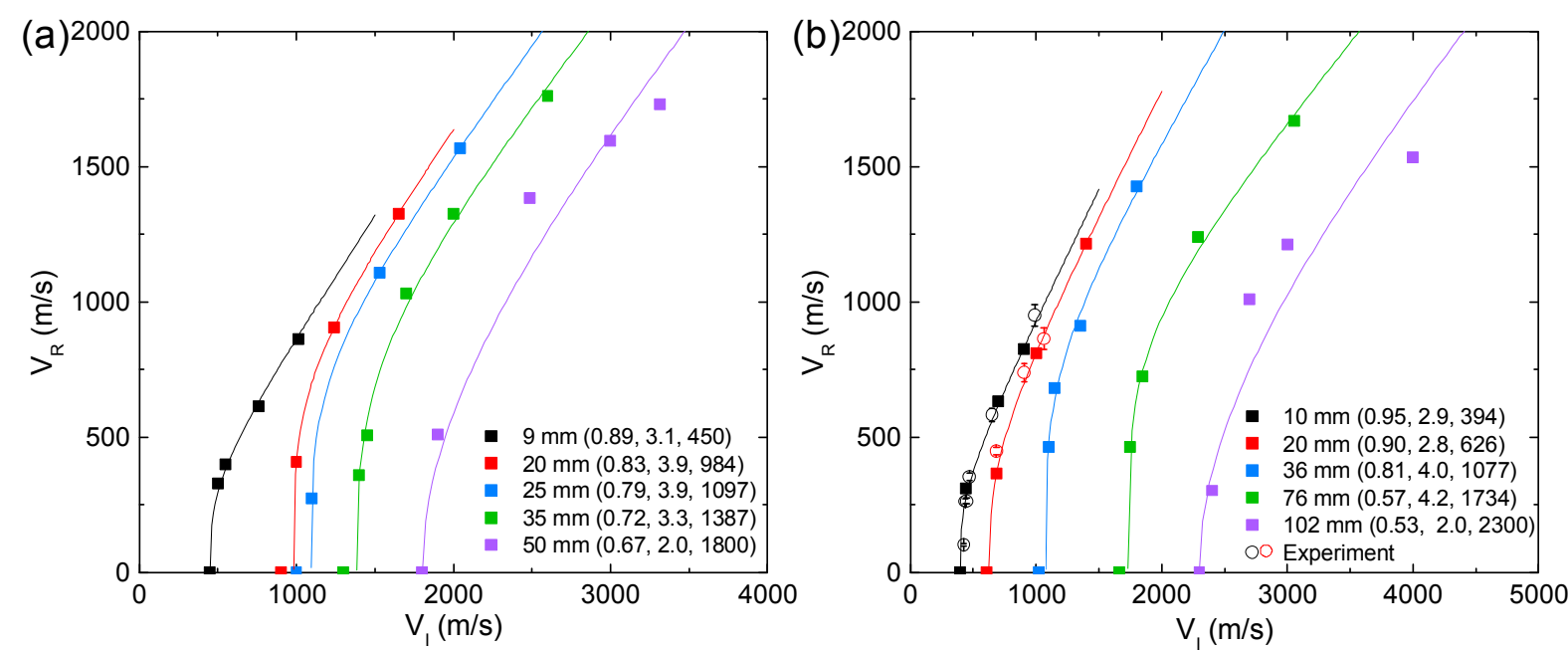

Figure 7: Numerical residual velocity predictions for UHMW-PE composite impacted by (a) $12.7 \mathrm{~mm}$ FSP and (b) $20 \mathrm{~mm}$ FSP with comparison to experimental measurements. The numerical results are fit to the Lambert-Jonas equation, parameters for which are given in the legend $\left(\mathrm{a}, \mathrm{p}, \mathrm{V}_{\mathrm{BL}}\right)$.

The numerical ballistic limit predictions, $V_{B L}$, are compared to experimental $\mathrm{V}_{50}$ results in Figure 8. The graph is plotted for both $12.7 \mathrm{~mm}$ and $20 \mathrm{~mm}$ FSP against UHMW-PE target thicknesses from $10 \mathrm{~mm}$ to $102 \mathrm{~mm}$ with respect to non-dimensional areal density (target areal density $\left(A D_{t}\right)$ multiplied by the projectile presented area $\left(A_{p}\right)$ divided by the projectile mass $\left.\left(m_{p}\right)\right)$. For thinner targets, the results are in excellent agreement with the experimental results. The results deviate slightly with increasing thickness and impact speed; however predictions are all within $20 \%$ of the experimental value and close to the experimental scatter range. A summary of the results showing the experimental $\mathrm{V}_{50}$, experimental standard deviation $\left(\sigma_{V 50}\right)$, numerical prediction $\left(\mathrm{V}_{\mathrm{BL}}\right)$ and range, and percentage difference $(\%$ Diff) between the calculated and measured limit values is given in Table 5 . 


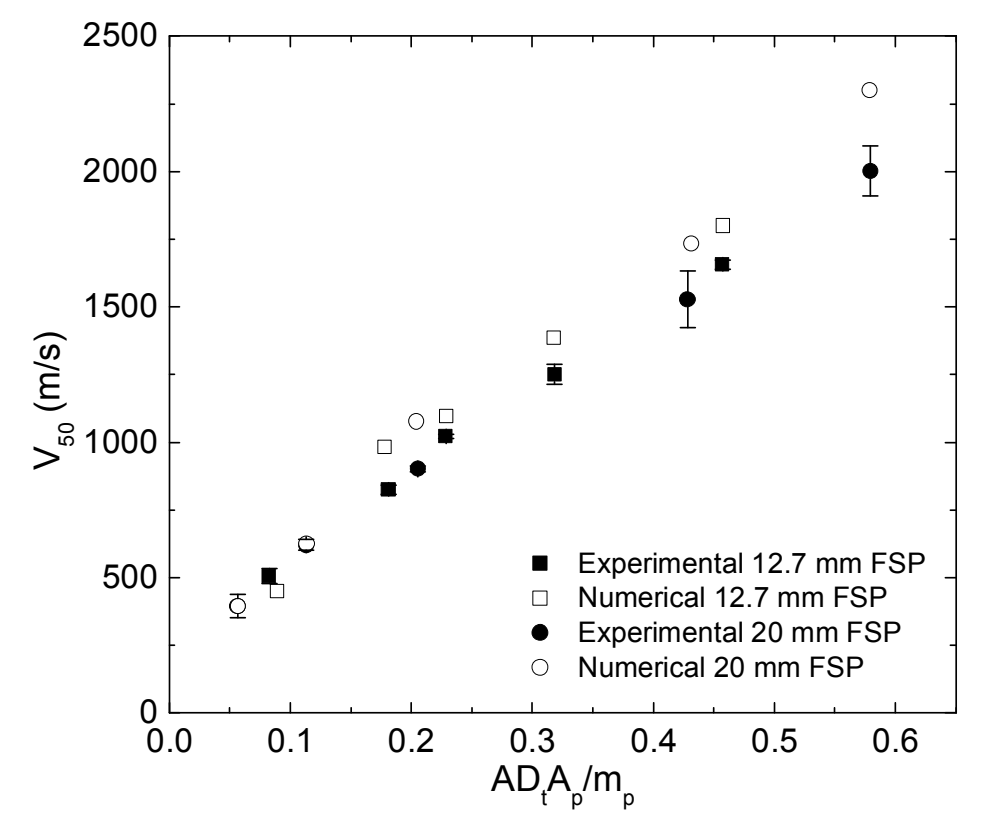

Figure 8: Experimental and numerical ballistic limit results plotted in terms of the nondimensional areal density

Table 5. Comparison between experimental and predicted ballistic limit

\begin{tabular}{cccccccc}
\hline $\begin{array}{c}\text { Target } \\
\text { Thickness }(\mathrm{mm})\end{array}$ & Threat & $\begin{array}{c}\mathrm{V}_{50} \\
(\mathrm{~m} / \mathrm{s})\end{array}$ & $\begin{array}{c}\sigma_{\mathrm{V} 50} \\
(\mathrm{~m} / \mathrm{s})\end{array}$ & $\begin{array}{c}\text { No. of sub- } \\
\text { laminates in model }\end{array}$ & $\begin{array}{c}\mathrm{V}_{\mathrm{BL}} \\
(\mathrm{m} / \mathrm{s})\end{array}$ & $\begin{array}{c}\mathrm{V}_{\mathrm{BL}} \text { Range } \\
(\mathrm{m} / \mathrm{s})\end{array}$ & $\%$ Diff \\
\hline 9.1 & $12.7 \mathrm{~mm}$ FSP & 506 & 26 & 7 & 450 & $450-500$ & -11.1 \\
20 & $12.7 \mathrm{~mm}$ FSP & 826 & 17 & 14 & 984 & $900-1000$ & 19.1 \\
25.2 & $12.7 \mathrm{~mm}$ FSP & 1021 & 8 & 18 & 1096 & $1000-1100$ & 7.3 \\
35.1 & $12.7 \mathrm{~mm}$ FSP & 1250 & 36 & 25 & 1387 & $1300-1400$ & 11 \\
50.4 & $12.7 \mathrm{~mm} \mathrm{FSP}$ & 1657 & 16 & 36 & 1800 & $1800-1900$ & 8.6 \\
10 & $20 \mathrm{~mm} \mathrm{FSP}$ & 394 & 43 & 5 & 394 & $394-440$ & 0 \\
20 & $20 \mathrm{~mm}$ FSP & 620 & 20 & 10 & 626 & $605-684$ & 1 \\
36.2 & $20 \mathrm{~mm}$ FSP & 901 & 10 & 18 & 1077 & $1020-1100$ & 19.5 \\
75.6 & $20 \mathrm{~mm}$ FSP & 1528 & 105 & 36 & 1734 & $1660-1750$ & 13.5 \\
101.7 & $20 \mathrm{~mm}$ FSP & 2002 & 92 & 51 & 2300 & $2300-2400$ & 14.9 \\
\hline
\end{tabular}

For numerical modelling of impacts just below the ballistic limit, one or more sub-laminates often delaminated fully from the target and were carried along with the projectile. Since the target was not perforated, this was considered a partial penetration result with a residual projectile velocity of $0 \mathrm{~m} / \mathrm{s}$. This was also observed in the ballistic experiments performed in Nguyen et al. [11], although the extent of delamination is not as significant. In the experiment, fibre bridging between sub-laminates provides significant resistance to complete delamination and therefore detachment of a subsection of the laminate. In the numerical 
model, fibre bridging is not described, so the resistance of the sub-laminates to complete detachment is lower. This may explain the tendency of the numerical model to over-predict the ballistic limit, particularly for thicker targets with increasing numbers of sub-laminate interfaces, see Figure 9. Another reason for the over-prediction may be a lack of a thermal softening model, which describes the degradation of the mechanical properties of the composite. Important material properties such as the tensile strength and elastic modulus of UHMW-PE fibres, which are directly related to its ballistic performance [11], are degraded under thermal loads [31]. Under ballistic impact, thermal loads arise due to shock induced heating and plastic deformation of the material. Fibre and matrix melting have been observed around the penetration cavity of UHMW-PE composite targets [32] and post impact analysis of targets from test in [11] show targets impacted at higher velocities (or thicker targets) show greater levels of melting. The degradation in material hardening and failure strength is not account for using this current modelling approach.
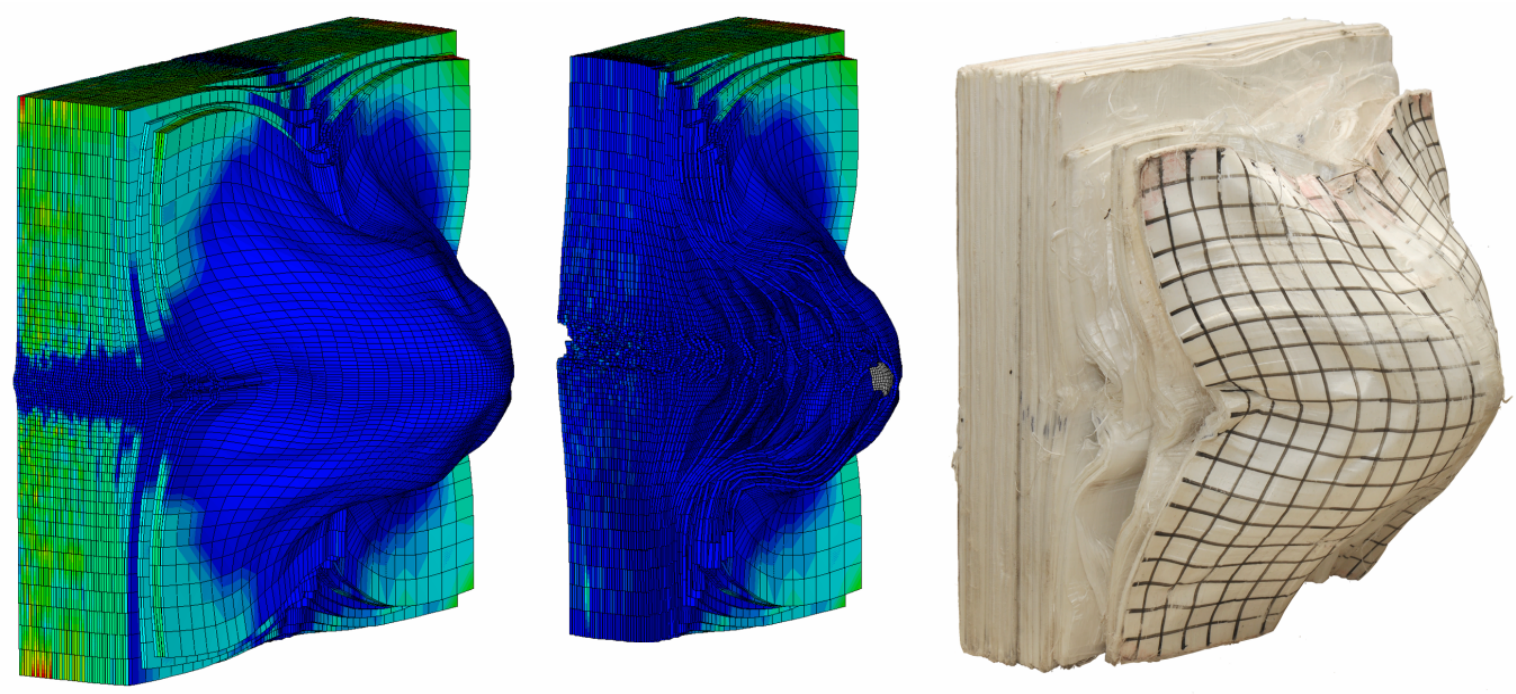

Figure 9. A $102 \mathrm{~mm}$ thick target impacted by a $20 \mathrm{~mm}$ FSP below the ballistic limit. Numerical simulation at an impact velocity of $2200 \mathrm{~m} / \mathrm{s}$ shown $750 \mu$ s after impact. Full target (left) and cross-section of target (middle). The contours represent the status of the sublaminate bonded interfaces with dark blue indicating failure. Post-test sample of target impacted at $1966 \mathrm{~m} / \mathrm{s}$ showing complete delamination of sub-laminates (right). 
Previous works [11] found that thick UHMW-PE composite targets (typically $>10 \mathrm{~mm}$ ) are perforated in two successive stages by $12.7 \mathrm{~mm}$ and $20 \mathrm{~mm}$ FSPs; an initial stage characterised by localised deformation and failure, followed by a back face bulging stage. This is shown in the post-test target in Figure 9, where the back of the target forms a bulge and is detached from the front portion of the target, which experiences minimal global deformation. The transition between these two stages was identifiable because bulging of the back face caused the orthogonal fibres in contact with the projectile to be stretched and pulled in towards the centre. This plane separating the two modes of penetration was generally quite distinct and the proportion of the thickness undergoing the initial stage was measured and reported in [11] as the shear plugging thickness ratio. The same phenomenon was observed in the numerical model, and the ratio of the target penetrated under the initial stage was recorded and plotted with respect to the impact velocity in Figure 10.

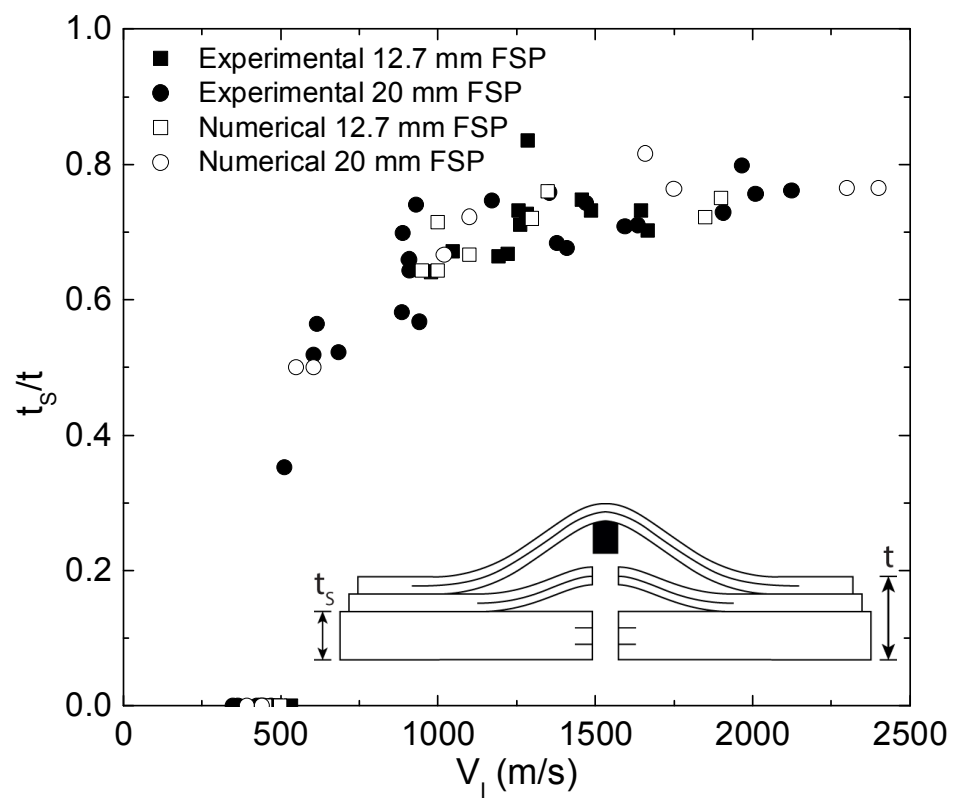

Figure 10. Ratio of target thickness penetrated in shear plugging $\left(t_{s}\right)$ to the total target thickness $(t)$, with respect to the impact velocity. 
For the numerical simulations, measurements were taken from one partial penetration and one complete perforation close to the ballistic limit for each target thickness and projectile combination. This is so a direct comparison can be made with the experimental results where the impact velocities were all very close to the $V_{50}$. Although there is a reasonable degree of scatter in both the experimental and numerical results, there is very good overall agreement between the two. Below impact velocities of around $500 \mathrm{~m} / \mathrm{s}$ the UHMW-PE composite targets respond entirely through bulging. With increased impact velocity, the proportion of the target penetrated by shear plugging increases rapidly until it begins to plateau at about $75 \%$ of the total thickness above $1200 \mathrm{~m} / \mathrm{s}$.

\subsubsection{Bulge development}

High energy ballistic impact on UHMW-PE composite causes the back face to deform in a typically pyramidal shape for a cross-ply layup, as shown for example in Figure 11. The velocity at which the hinge of the bulge propagates was investigated for UHMW-PE composite strips and thin targets (up to four plies) by Chocron et al. [33]. The propagation velocity of the hinge was found to be the same as the transverse wave velocity, which is predicted using classical yarn theory [34]. For thicker targets the position and velocity of the hinge is more difficult to predict because of the added complexities of target bending resistance, a longer penetration process, and a projectile that is being significantly decelerated. Prediction of the bulge apex is important as it is an indication of the projectile position and velocity as it penetrates the target. Furthermore the bulge apex is an important parameter for many protection applications (i.e. back face deformation). 

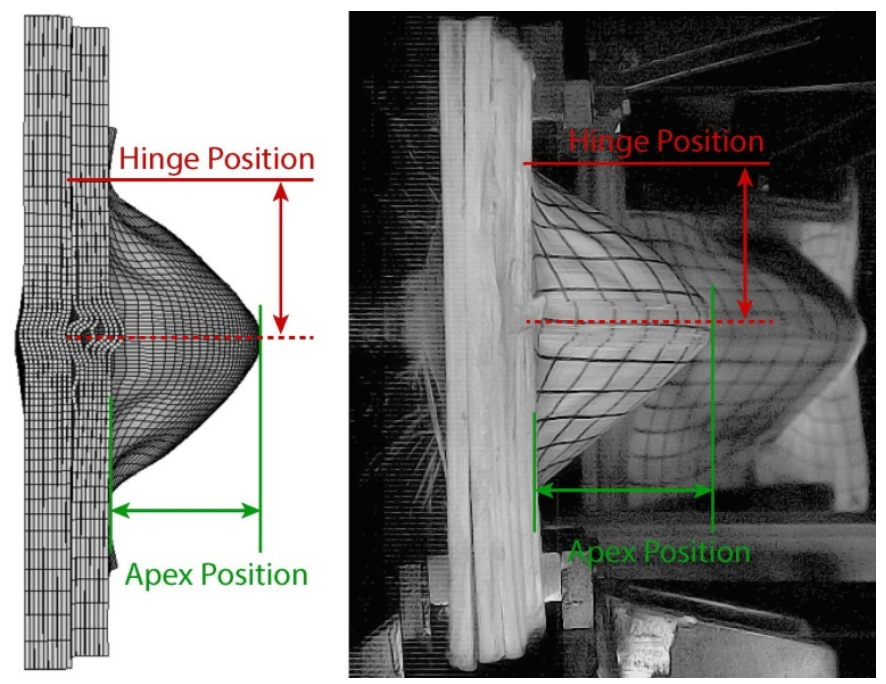

Figure 11. Numerical (left) and experimental (right) target response at $450 \mu \mathrm{s}$ after impact by $20 \mathrm{~mm} \mathrm{FSP}$ at $888 \mathrm{~m} / \mathrm{s}$.

The hinge and apex position of a bulge from $10 \mathrm{~mm}, 20 \mathrm{~mm}$ and $36 \mathrm{~mm}$ thick Dyneema ${ }^{\circledR}$ HB26 targets impacted by a 20 mm FSP just below the ballistic limit were measured in-situ using a high speed camera in [11]. In these tests, the camera was positioned with a side view of the target, and a mirror was used to provide a perspective view of the back face on the same frame (as shown in Figure 11). A grid was drawn on the back of the target and the camera was calibrated for position measurements.

The geometric deformation of the bugle is well replicated in the numerical model, as shown in Figure 11. Figure 12 compares the hinge and apex positions with time following projectile impact determined from experiment and numerical simulation. The development of the bulge apex is well predicted by the model for the $10 \mathrm{~mm}$ and $20 \mathrm{~mm}$ thick panels, but less accurate for the $36 \mathrm{~mm}$ thick panel. 

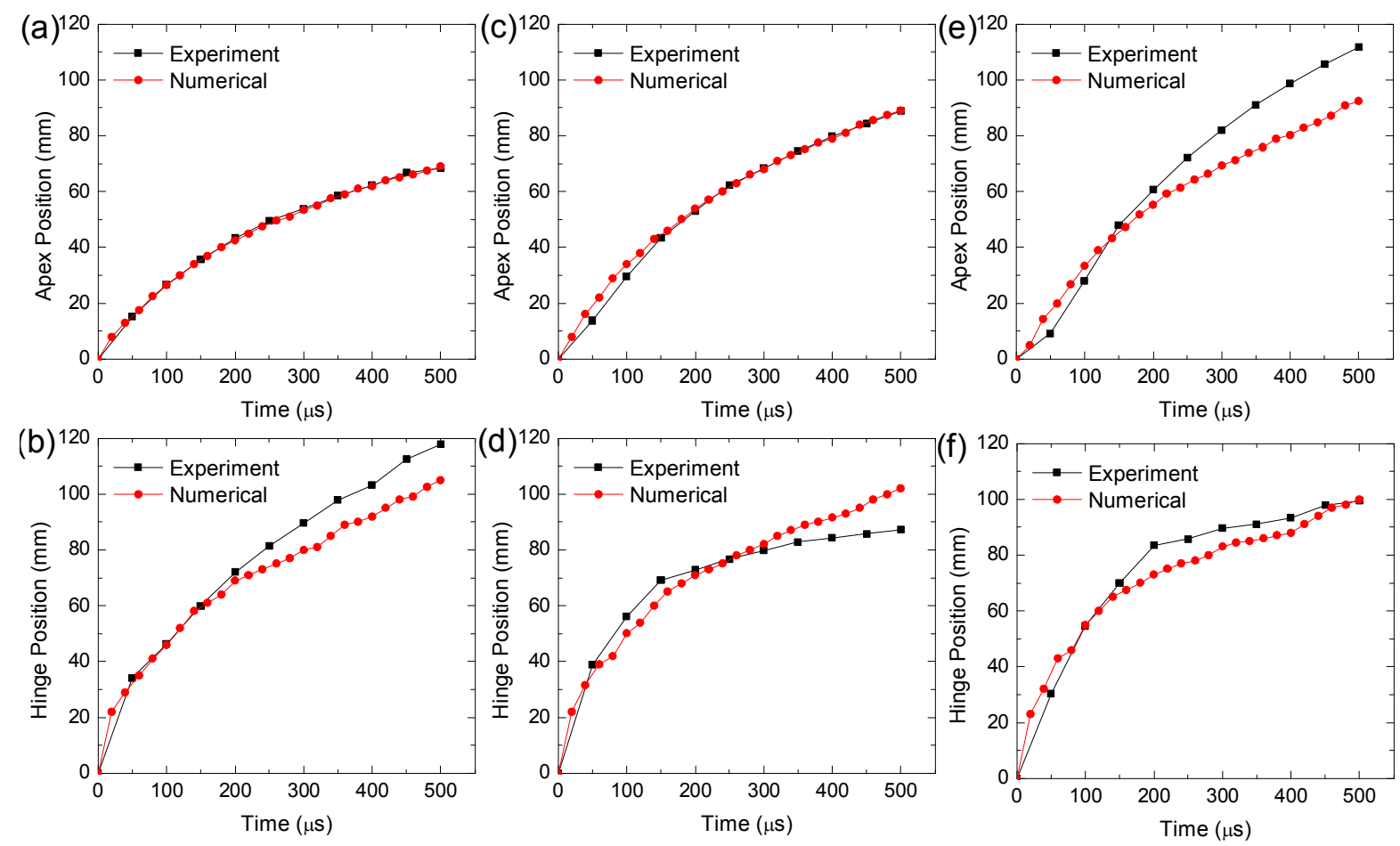

Figure 12: Bulge apex and hinge position with respect to time for $10 \mathrm{~mm}$ panel impacted at $365 \mathrm{~m} / \mathrm{s}$ (a)(b), $20 \mathrm{~mm}$ panel impacted at $615 \mathrm{~m} / \mathrm{s} \mathrm{(c)(d)} \mathrm{and} 36 \mathrm{~mm}$ panel impacted at 888 $\mathrm{m} / \mathrm{s}(\mathrm{e})(\mathrm{f})$ by a $20 \mathrm{~mm}$ FSP.

As shown in the previous section, the ballistic limit prediction were more accurate for the 10 $\mathrm{mm}$ and $20 \mathrm{~mm}$ thick targets against the $20 \mathrm{~mm}$ FSP (within $1 \%$ error in $\mathrm{V}_{50}$ prediction) while the $\mathrm{V}_{50}$ for the $36 \mathrm{~mm}$ target was over-predicted by up to $20 \%$ (due to more sublaminate interfaces and omission of thermal softening model as discussed above). The increased penetration resistance in the numerical model for the $36 \mathrm{~mm}$ thick target would be identified in the bulge growth by an under-prediction of the apex position, as seen in Figure 12(e). The hinge positions for the three cases investigated are in good agreement with experiment up to a hinge position of about $70 \mathrm{~mm}$. For larger hinge displacement, numerical predictions deviate from the experiment because the propagation of the hinge is affected by target clamping (which is not modelled) as it extends close to the target edge. If the target (which measures $300 \mathrm{~mm} \times 300 \mathrm{~mm}$ laterally) is impacted at the centre, the hinge can theoretically propagate up to $150 \mathrm{~mm}$. However the presence of the vice clamps on the top 
and bottom (as shown in Figure 11) of the target reduces this to about $100 \mathrm{~mm}$ for this configuration. Off-centre impact and resistance to rotation at the clamp edge can reduce further the zone where the hinge can propagate unimpeded.

\section{Conclusion}

An analysis methodology is proposed to model the behaviour of thick UHMW-PE composite panels under ballistic impact using the non-linear orthotropic model [7-9] in a commercial hydrocode. The approach provides a new material data set and improves on existing modelling methods by using sub-laminate discretisation of the target to better model delamination failure. It is introduced together with a newly implemented damage based erosion model which is more suitable for anisotropic materials.

The methodology was extensively validated against existing experimental ballistic impact data and results for UHMW-PE targets up to $102 \mathrm{~mm}$ thick. Depth of penetration into semiinfinite targets against $20 \mathrm{~mm}$ FSPs was predicted to within 3\% of experimental values. Ballistic limit and residual velocity predictions were also in good agreement with experimental measurements, with the ballistic limit predictions within $20 \%$ for all conditions considered. The error may be attributed to the omission of both fibre bridging between the sub-laminate interfaces and possible thermal softening which is not prescribed by the numerical model. The two stages of penetration exhibited by thick UHMW-PE composite targets are well replicated with the model, which gives good predictions of the shear plugging thickness ratio. The bulge development of UHMW-PE composite under ballistic impact is accurately modelled in terms of the bulge hinge and apex position.

\section{Acknowledgement}

The work reported herein was funded by the Defence Science and Technology Organisation (DSTO) under the Land Vehicle Survivability Science and Technology Capability (STC). In 
this the authors would like to thank Dr Stephan Cimpoeru from DSTO for his advice and support of this work program. The authors would also like to acknowledge the support of both RMIT University and the Defence Materials Technology Centre (DMTC) in providing a $\mathrm{PhD}$ scholarship to the lead author. The DMTC was established and is supported by the Australian Government's Defence Future Capability Technology Centre (DFCTC) initiative. Dr Ulrich Heisserer and Dr Harm van der Werff from DSM are acknowledged for providing some of the mechanical test data and insightful discussions.

\section{Reference}

[1] Nguyen LH, Ryan S, Cimpoeru SJ, Mouritz AP, Orifici AC. The efficiency of ultrahigh molecular weight polyethylene against fragment impact. Exp Mech 2015. doi:10.1007/s11340-015-0051-z.

[2] Lässig T, Nguyen L, May M, Riedel W, Heisserer U, van der Werff H, et al. A nonlinear orthotropic hydrocode model for ultra-high molecular weight polyethylene in impact simulations. Int J Impact Eng 2015;75:110-22. doi:10.1016/j.ijimpeng.2014.07.004.

[3] Chocron S, Nicholls AE, Brill A, Malka A, Namir T, Havazelet D, et al. Modeling unidirectional composites by bundling fibers into strips with experimental determination of shear and compression properties at high pressures. Compos Sci Technol 2014;101:32-40. doi:10.1016/j.compscitech.2014.06.016.

[4] Grujicic M, Arakere G, He T, Bell WC, Glomski PS, Cheeseman BA. Multi-scale ballistic material modeling of cross-plied compliant composites. Compos Part B Eng 2009;40:468-82. doi:10.1016/j.compositesb.2009.02.002.

[5] Bürger D, Faria A, Almeida S, Melo F, Donadon M. Ballistic impact simulation of an armour-piercing projectile on hybrid ceramic / fiber reinforced composite armours. Int J Impact Eng 2012;43:63-77. doi:10.1016/j.ijimpeng.2011.12.001.

[6] Hayhurst CJ, Hiermaier SJ, Clegg RA, Riedelt W, Lambert M. Development of material models for nextel and kevlar-expoxy for high pressures and strain rates. Int $\mathrm{J}$ Impact Eng 1999;23:365-76.

[7] Clegg RA, White DM, Riedel W, Harwick W. Hypervelocity impact damage prediction in composites: Part I - material model and characterisation. Int J Impact Eng 2006;33:190-200. doi:10.1016/j.ijimpeng.2006.09.055. 
[8] Riedel W, Nahme H, White DM, Clegg RA. Hypervelocity impact damage prediction in composites: Part II - experimental investigations and simulations. Int J Impact Eng 2006;33:670-80. doi:10.1016/j.ijimpeng.2006.09.052.

[9] Wicklein M, Ryan S, White DM, Clegg RA. Hypervelocity impact on CFRP: Testing, material modelling, and numerical simulation. Int J Impact Eng 2008;35:1861-9. doi:10.1016/j.ijimpeng.2008.07.015.

[10] Nguyen LH, Lässig TR, Ryan S, Riedel W, Mouritz AP, Orifici AC. Numerical Modelling of Ultra-High Molecular Weight Polyethylene Composite under Impact Loading. Procedia Eng 2015;103:436-43. doi:10.1016/j.proeng.2015.04.043.

[11] Nguyen LH, Ryan S, Cimpoeru SJ, Mouritz AP, Orifici AC. The effect of target thickness on the ballistic performance of ultra high molecular weight polyethylene composite. Int J Impact Eng 2015;75:174-83. doi:10.1016/j.ijimpeng.2014.07.008.

[12] ANSYS. AUTODYN Composite Modelling Release 15.0. Canonsburg: 2013.

[13] DSM. Fact Sheet: Dyneema high strength, high modulus polyethylene fiber 2008.

[14] Heisserer U. Dyneema ${ }^{\circledR}$ material information for ballistic modeling. Geleen: 2013.

[15] Los Alamos. Selected Hugoniots. New Mexico: 1969.

[16] Riedel W, Nahme H, Thoma K. Equation of State Properties of Modern Composite Materials Modeling Shock, Release and Spallation. Shock Compression Condens. Matter, 2004, p. 701-4.

[17] Wilkins M. Calculation of elastic-plastic flow. California: 1963.

[18] Anderson C, Cox P, Johnson G, Maudlin P. A constitutive formulation for anisotropic materials suitable for wave propagation computer programs-II. Comput Mech 1994;15:201-23. doi:10.1007/BF00375030.

[19] Hazell PJ, Appleby-Thomas GJ, Trinquant X, Chapman DJ. In-fiber shock propagation in Dyneema. J Appl Phys 2011;110:043504.

[20] Chen JK, Allahdadi F a., Sun CT. A Quadratic Yield Function for Fiber-Reinforced Composites. J Compos Mater 1997;31:788-811. doi:10.1177/002199839703100803.

[21] Lassig T. Dynamic characterization and modeling of Dyneema. Freiburg: 2012.

[22] Kellas S, Morton J, Jackson KE. Damage and failure mechanisms in scaled angle-ply laminates. Compos Mater Fatigue Fract 1993;4:257-80.

[23] Chocron S, Anderson CE, Grosch DJ, Popelar CH. Impact of the 7.62-mm APM2 projectile against the edge of a metallic target. Int J Impact Eng 2001;25:423-37. doi:10.1016/S0734-743X(00)00063-4.

[24] ANSYS. ANSYS Mechanical User's Guide. Release 15. Pennsylvania: 2013. 
[25] Qi H, Boyce M. Stress-strain behavior of thermoplastic polyurethanes. Mech Mater 2005;37:817-39. doi:10.1016/j.mechmat.2004.08.001.

[26] Vyas GM, Pinho ST, Robinson P. Constitutive modelling of fibre-reinforced composites with unidirectional plies using a plasticity-based approach. Compos Sci Technol 2011;71:1068-74. doi:10.1016/j.compscitech.2011.03.009.

[27] Department of Defense. MIL-DTL-46593B: Projectile, calibre .22, .30, .50, and 20 mm fragment simulating. 2006.

[28] Johnson G, Cook W. A constitutive model and data for metals subjected to large strains, high strain rates and high temperatures. Proc 7th Int Symp Ballist 1983;547:541-7.

[29] Yen CF. A ballistic material model for continuous-fiber reinforced composites. Int J Impact Eng 2012;46:11-22. doi:10.1016/j.ijimpeng.2011.12.007.

[30] Lambert JP, Jonas GH. Towards standardization in terminal ballistic testing: velocity representation. Army Ballistic Reseach Lab: 1976.

[31] Dessain B, Moulaert O, Keunings R, Bunsell AR. Solid phase change controlling the tensile and creep behaviour of gel-spun high-modulus polyethylene fibres. J Mater Sci 1992;27:4512-22.

[32] Greenhalgh ES, Bloodworth VM, Iannucci L, Pope D. Fractographic observations on Dyneema ${ }^{\circledR}$ composites under ballistic impact. Compos Part A Appl Sci Manuf 2013;44:51-62. doi:10.1016/j.compositesa.2012.08.012.

[33] Chocron S, King N, Bigger R, Walker JD, Heisserer U, van der Werff H. Impacts and Waves in Dyneema ${ }^{\circledR}$ HB80 Strips and Laminates. J Appl Mech 2013;80:031806. doi:10.1115/1.4023349.

[34] Smith JC, McCrackin FL, Schiefer HF. Stress-Strain Relationships in Yarns Subjected to Rapid Impact Loading: Part V: Wave Propagation in Long Textile Yarns Impacted Transversely. Text Res J 1958;28:288-302. doi:10.1177/004051755802800402. 